Article

\title{
Surface Analysis of Biodegradable Mg-Alloys after Immersion in Simulated Body Fluid
}

\author{
Darja Steiner Petrovič ${ }^{1, *}$, Djordje Mandrino ${ }^{1}$, Božidar Šarler ${ }^{1,2}{ }^{\oplus}$, Jelena Horky ${ }^{3}$, \\ Andrea Ojdanic ${ }^{4}$, Michael J. Zehetbauer ${ }^{4}$ and Dmytro Orlov ${ }^{5}$
}

1 Physics and Chemistry of Materials, and Simulation of Materials and Processes, Institute of Metals and Technology, Lepi pot 11, 1000 Ljubljana, Slovenia; Djordje.Mandrino@imt.si (D.M.);

Bozidar.Sarler@imt.si (B.Š.)

2 Department of Fluid Dynamics and Thermodynamics, Faculty of Mechanical Engineering, University of Ljubljana, Aškerčeva 6, 1000 Ljubljana, Slovenia

3 Center for Health \& Bioresources, Biomedical Systems, AIT Austrian Institute of Technology, Viktor Kaplan Straße 2, 2700 Wiener Neustadt, Austria; Jelena.Horky@ait.ac.at

4 Physics of Nanostructured Materials, Faculty of Physics, University of Vienna, Boltzmanngasse 5, 1090 Vienna, Austria; Andrea.Ojdanic@univie.ac.at (A.O.); Michael.Zehetbauer@univie.ac.at (M.J.Z.)

5 Division of Materials Engineering, Department of Mechanical Engineering, Faculty of Engineering (LTH), Lund University, Ole Römers väg 1, 22363 Lund, Sweden; Dmytro.Orlov@material.lth.se

* Correspondence: Darja.Steiner@imt.si; Tel.: +386-1470-1968

Received: 13 March 2020; Accepted: 6 April 2020; Published: 8 April 2020

\begin{abstract}
Two binary biodegradable Mg-alloys and one ternary biodegradable $\mathrm{Mg}$-alloy $(\mathrm{Mg}-0.3 \mathrm{Ca}$, $\mathrm{Mg}-5 \mathrm{Zn}$ and $\mathrm{Mg}-5 \mathrm{Zn}-0.3 \mathrm{Ca}$, all in wt\%) were investigated. Surface-sensitive X-ray photoelectron spectroscopy analyses (XPS) of the alloy surfaces before and after immersion in simulated body fluid (SBF) were performed. The XPS analysis of the samples before the immersion in SBF revealed that the top layer of the alloy might have a non-homogeneous composition relative to the bulk. Degradation during the SBF immersion testing was monitored by measuring the evolution of $\mathrm{H}_{2}$. It was possible to evaluate the thickness of the sample degradation layers after the SBF immersion based on scanning electron microscopy (SEM) of the tilted sample. The thickness was in the order of 10-100 $\mu \mathrm{m}$. The typical bio-corrosion products of all of the investigated alloys consisted of $\mathrm{Mg}, \mathrm{Ca}, \mathrm{P}$ and $\mathrm{O}$, which suggests the formation of apatite (calcium phosphate hydroxide), magnesium hydrogen phosphate hydrate and magnesium hydroxide. The bioapplicability of the analyzed alloys with regard to surface composition and degradation kinetics is discussed.
\end{abstract}

Keywords: biodegradable Mg alloy; corrosion; X-ray photoelectron spectroscopy; phosphate; apatite; degradation layer

\section{Introduction}

Artificial materials considered to be suitable for applications as implants are commonly tested in vivo and by in vitro methods in media that simulate body fluids. These tests are focused on an examination of the physical, chemical and mechanical properties of the materials and thus provide the basic information needed to judge their suitability for clinical use in the human body [1]. Currently, magnesium-based biodegradable alloys are gaining importance as temporary implant materials in orthopedic applications [2-4]. Their elastic properties are similar to those of bones, and their in vivo biodegradability through corrosion makes them candidates for different biomedical applications such as biocompatible, osteoconductive, degradable implants for load-bearing and bone repairing [5]. The major drawback of using $\mathrm{Mg}$ alloys as implant materials is their too-high corrosion rate in 
a physiological environment, which can impair their mechanical properties [6-9]. This is mainly addressed by surface coating and optimizing the alloying of $\mathrm{Mg}$ [10-13].

One of the alloying elements used for $\mathrm{Mg}$ is $\mathrm{Ca}$, and both are crucial for the formation of human bone [3,6,14-17]. Mg and $\mathrm{Ca}$ are essential quantity elements and represent two of the four main electrolytes that constitute about $1.89 \%$ of an average human body, while the remaining $0.02 \%$ is made up of eleven typical trace elements. $\mathrm{Zn}$ is an essential trace element and can be found in all body tissues, with $85 \%$ of all of the body's zinc in the bone and muscle [18]. $\mathrm{Zn}$ is known to have a positive impact on bone healing and cell reactions [19].

It has been established that $\mathrm{Mg}$-Ca alloys have good biocompatibility due to their degradation in bone $[3,16,17]$. Mg alloys with $\mathrm{Ca}$ or $\mathrm{Zn}$, or ternary $\mathrm{Mg}-\mathrm{Zn}-\mathrm{Ca}$ alloys, also possess highly favorable mechanical properties $[5,17,20-22]$.

In this study, two binary (Mg-0.3Ca and $\mathrm{Mg}-5 \mathrm{Zn}$ ) alloys and one ternary (Mg-5Zn-0.3Ca) alloy were investigated as-cast and homogenized, after in vitro bio-corrosion immersion tests in simulated body fluid (SBF). The chemical reaction took place during immersion, as observed by hydrogen evolution. Reaction products in the form of surface-degradation layers were formed on all of the alloys. These degradation layers were analyzed in detail.

\section{Experimental}

\subsection{Materials and Sample Preparation}

Three $\mathrm{Mg}$ alloys, two binary (Mg-0.3Ca and Mg-5Zn, i.e., X03 and Z5, respectively) and one ternary (Mg-5Zn-0.3Ca, i.e., ZX50), with compositions as given in Table 1, were processed as follows: the alloys were cast at the LKR Leichtmetallkompetenzzentrum Ranshofen, Austria, a subsidiary of the AIT Austrian Institute of Technology. From the cast billets with diameters of $50 \mathrm{~mm}$, samples were prepared as disks of magnesium alloys with diameter $\phi=10 \mathrm{~mm}$ and height $\mathrm{h}=0.7 \mathrm{~mm}$. They were solid-solution treated at $450{ }^{\circ} \mathrm{C}$ for $24 \mathrm{~h}$ in the case of the $\mathrm{Mg}$-Ca and $\mathrm{Mg}-\mathrm{Zn}-\mathrm{Ca}$, and at $350{ }^{\circ} \mathrm{C}$ for $12 \mathrm{~h}$ in the case of the $\mathrm{Mg}-\mathrm{Zn}$. Before immersion into the SBF, with the composition given in Table 2 (i.e., SBF27 from [1]), the samples were polished down to 1200-grit SiC paper and cleaned with ethanol to minimize the oxidation layer and to obtain a defined surface condition before testing.

Table 1. The chemical compositions of the alloys in $\mathrm{wt} \%$ and at $\%$, as measured by $\mathrm{X}$-ray Fluorescence Spectroscopy (XFS) before immersion into simulated body fluid (SBF).

\begin{tabular}{ccccccc}
\hline Nominal Composition & \multicolumn{2}{c}{ Mg-0.3Ca } & \multicolumn{2}{c}{ Mg-5Zn } & \multicolumn{2}{c}{ Mg-5Zn-0.3Ca } \\
\hline Naming Convention & \multicolumn{2}{c}{ X03 } & \multicolumn{2}{c}{ Z5 } & \multicolumn{2}{c}{ ZX50 } \\
\hline Measured Composition & wt $\%$ & at $\%$ & wt $\%$ & at $\%$ & wt $\%$ & at $\%$ \\
\hline Ca & 0.3 & 0.2 & - & - & 0.3 & 0.2 \\
Zn & - & - & 5.0 & 1.9 & 5.0 & 1.9 \\
$\mathbf{M g}$ & 99.7 & 99.8 & 95.0 & 98.1 & 94.7 & 97.9 \\
\hline
\end{tabular}

Table 2. The composition of SBF (ionic concentrations in $\mathrm{mmol} / \mathrm{L}$ ) [1].

\begin{tabular}{ccccccccc}
\hline Ion & $\mathbf{N a}^{+}$ & $\mathrm{K}^{+}$ & $\mathbf{M g}^{2+}$ & $\mathrm{Ca}^{2+}$ & $\mathbf{C l}^{-}$ & $\mathbf{H C O}_{3}{ }^{-}$ & $\mathbf{H P O}_{4}{ }^{2-}$ & $\mathbf{S O}_{4}{ }^{2-}$ \\
\hline Concentration & 142.0 & 5.0 & 1.0 & 2.5 & 109.0 & 27.0 & 1.0 & 0.5 \\
\hline
\end{tabular}

All of the corrosion experiments were conducted at body temperature, and a Tris/ $\mathrm{HCl}$ buffer was used to adjust the $\mathrm{pH}$ of the SBF to an initial value of approximately 7.4. Two samples were always immersed together in $250 \mathrm{~mL}$ of SBF. The SBF was replaced with a fresh batch every 7 days, and the whole test was conducted for 21 days. 


\subsection{Monitoring the Corrosion Reaction in SBF}

As a measure of the reaction progress of the alloy in the SBF, the evolving hydrogen gas was collected in a glass cylinder, and the amount was recorded every $4 \mathrm{~h}$. The corrosion rate was calculated by normalizing the volume of hydrogen gas to the initial sample surface area and applying a numerical derivation. Then, the curves were smoothed using a moving average algorithm. An average of at least two independent measurements was calculated.

\subsection{Surface Analyses}

Before analyses, visual inspection of the surfaces was performed using a stereo microscope, Olympus. X-ray Photoelectron Spectroscopy (XPS) was used for the surface analyses of the samples. A Microlab 310 F VG-Scientific SEM/AES/XPS instrument ((VG Scientific Ltd., East Grinstead, UK)) was used. Images were recorded using Scanning Electron Microscopy (SEM). Due to the strong charging of the sample's surface, the best-quality information was obtained by XPS, which provided the chemical composition of the surface and the chemical states of the individual elements, thus suggesting possible compounds.

For all of the XPS measurements, Al-K $\alpha$ radiation at $1486.6 \mathrm{eV}$, with an anode voltage of $12.5 \mathrm{kV}$ and an emission current of $16 \mathrm{~mA}$ (total power of $200 \mathrm{~W}$ ), was used. The $\mathrm{C} 1 \mathrm{~s}$ beneficial contamination peak at $284.7 \mathrm{eV}$ was used for the energy-scale calibration. Pass energies of 20 and $100 \mathrm{eV}$ were used for the survey and high-resolution measurements. The step size used in the high-resolution measurements was $200 \mathrm{meV}$, with up to 20 scans averaged in the measurement of one spectrum. The measurements and data acquisition were controlled with the Avantage 3.41v data-acquisition and processing software supplied by the SEM/AES/XPS equipment manufacturer. The commercially available Casa XPS software (Version 2.3.15, Casa Software Ltd., Teignmouth, UK) for XPS and AES data processing [23] was also used for further data processing, e.g., fitting the high-resolution peaks using components corresponding to the different chemical states of the elements. Reference XPS data were taken from [24,25].

\subsubsection{Experimental Parameters Specific to XPS Analyses before Immersion Testing}

Before the XPS measurements, the sample surfaces were sputtered in cycles of $30 \mathrm{~min}(1800 \mathrm{~s})$ for up to $90 \mathrm{~min}(5400 \mathrm{~s})$ using an $\mathrm{Ar}^{+}$ion beam of $3 \mathrm{keV}$ with a $0.8-\mu \mathrm{A}$ ion current over a $20 \mathrm{~mm}^{2}$ area, with a sputtering rate of approximately $0.15 \mathrm{~nm} / \mathrm{min}$. After each sputtering cycle, a quick XPS was taken, and when the $C$ 1s stopped decreasing, the sputtering was stopped. With the parameters used, this corresponded to removing approximately $15 \mathrm{~nm}$ from the top of the sample.

\subsubsection{Experimental Parameters Specific to XPS Analyses after Immersion Testing}

The XPS measurements were performed after sputtering with $\mathrm{Ar}^{+}$ions in steps of $900 \mathrm{~s}$ for total sputtering times of up to $60 \mathrm{~min}(3600 \mathrm{~s})$. An $\mathrm{Ar}^{+}$beam of $3 \mathrm{keV}$ was used at a $0.8-\mu \mathrm{A}$ ion current over a square area of $16 \mathrm{~mm}^{2}$. At these parameters, the sputtering rate was approximately $0.2 \mathrm{~nm} / \mathrm{min}$, which means that after $60 \mathrm{~min}$ of sputtering, approximately $15 \mathrm{~nm}$ of material was removed from the surface.

\section{Results}

\subsection{Analysis of Samples before Corrosion Testing}

\subsubsection{Imaging}

The surfaces of the representative samples, provided for XPS analysis before immersion in SBF, can be seen in Figure 1. 


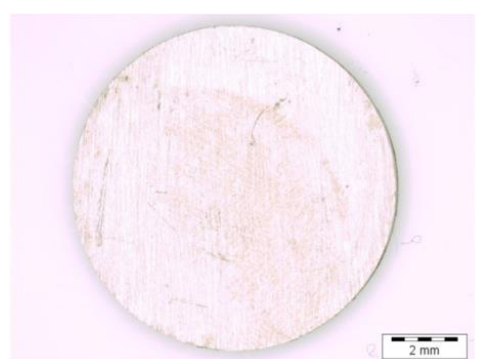

(a)

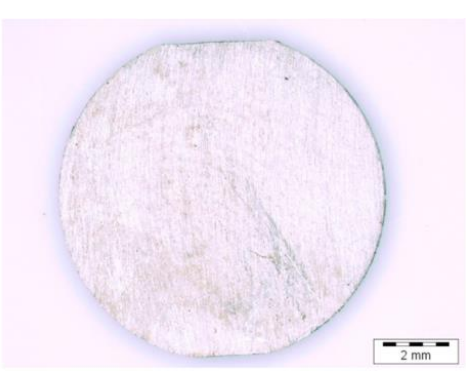

(b)

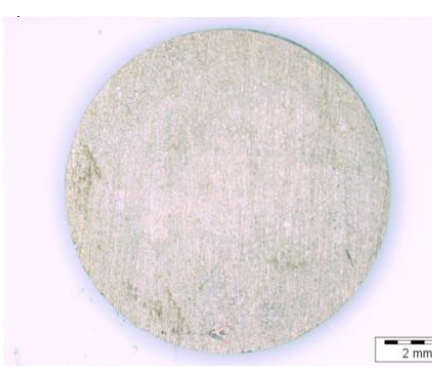

(c)

Figure 1. Stereo microscope images of representative samples X03 (a), Z5 (b) and ZX50 (c) before immersion in SBF.

\subsubsection{XPS of Samples before SBF Immersion}

The surfaces of two binary alloys, X03 and Z5, and one ternary alloy, ZX50, were investigated by XPS before the bio-corrosion immersion tests in the SBF. Figure 2 shows that apparently all of the sputter cleaning is already achieved after the first sputtering cycle. Full XPS spectra after the final sputtering cycle are shown in Figure 3.

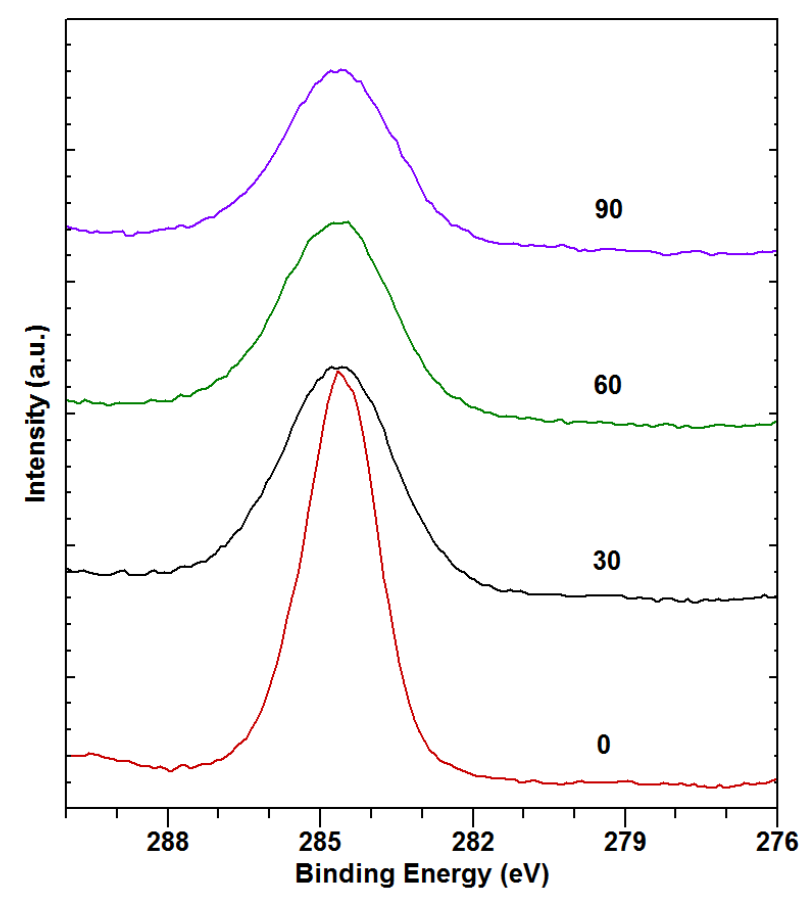

Figure 2. Typical C 1s peak intensities after different sputtering times (in minutes).

Comparing the spectra of the sputtered samples (Figure 3), the following is observed: Mg appears on the surface of all of the samples. The binding energies are consistent with $\mathrm{Mg}$ oxides, phosphates and carbonates. Low-intensity Si $2 p$ and Si 2 s peaks are also observed. They most probably stem from contamination by silicon oil during the preparation of the sample. This is supported by the fact that no $\mathrm{Si}$ was detected in the initial composition of the samples. As expected, $\mathrm{Ca}$ is not observed in Z5. In X03 and ZX50, the binding energies are consistent with Ca oxides, carbonates, phosphates and silicates. Several $\mathrm{O}$ components appear in all of the samples, with binding energies consistent with different oxides, carbonates and phosphates. No $\mathrm{Zn}$ is observed in any sample. The small concentration of $\mathrm{Zn}$ (only 1.9 at $\%$, see Table 1) suggests that the acquisition time, even for the $Z n$ 2p peaks (Zn 2p3/2 at 1023 $\mathrm{eV}$ and $\mathrm{Zn} 2 \mathrm{p} 1 / 2$ at $1046 \mathrm{eV}$, the most intense of all $\mathrm{Zn}$ transitions), was too short. On the other hand, $\mathrm{Ca}$ 2s peaks, which should be of roughly the same intensity, are observed. This suggests that the surface 
layer of the sample is significantly enriched with Ca compared to the bulk (Table 3). Additionally, partial $\mathrm{Zn}$ depletion of the surface layer is also possible. Since no phosphorus is detected, it can be concluded that the surface is predominantly covered with an oxide layer, since no carbonate peak is observed in C 1s (Figure 2).

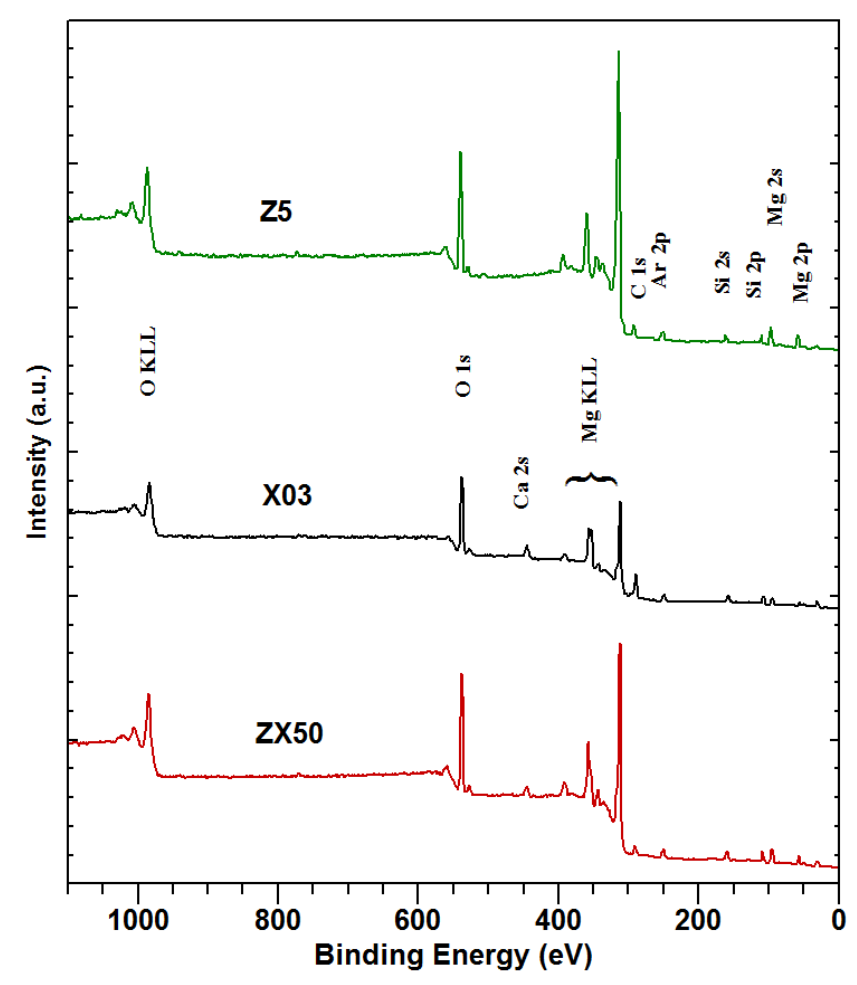

Figure 3. Survey X-ray photoelectron spectroscopy (XPS) spectra of sputtered samples ZX50 (Mg-0.3Ca-5Zn), X03 (Mg-0.3Ca) and Z5 (Mg-5Zn) before immersion in SBF.

Table 3. The binding energies (BE) and atomic concentrations in the measured samples. Different components of $\mathrm{O}$ correspond to different compounds of $\mathrm{O}$.

\begin{tabular}{ccccccc}
\hline Sample & \multicolumn{2}{c}{ X03 } & \multicolumn{2}{c}{ Z5 } & \multicolumn{2}{c}{ ZX50 } \\
\hline XPS Peak & BE/eV & c/at\% & BE/eV & c/at\% & BE/eV & c/at\% \\
\hline Ca 2s & 440.3 & 12.9 & - & - & 439.4 & 6.0 \\
Mg 2s & 90.4 & 25.7 & 89.7 & 40.7 & 89.8 & 36.0 \\
O 1s 1 & 532.4 & 53.1 & 531.9 & 52.6 & 532.0 & 48.4 \\
O 1s 2 & 529.9 & 1.0 & 530.5 & 3.0 & 531.5 & 2.8 \\
O 1s 3 & 533.5 & 6.4 & 533.6 & 5.9 & 533.5 & 6.8 \\
\hline
\end{tabular}

Comparing Tables 1 and 3, a drastic Ca enrichment in the surfaces of Ca-containing samples can be found. This could be due to Ca precipitation on the surface and/or the leaching of $\mathrm{Mg}$ and $\mathrm{Zn}$ during polishing. A similar effect has been observed by Liu et al., where the Ca concentration in precipitates was an order of magnitude higher than in the matrix [6].

\subsection{Evolution of the Corrosion Reaction with Time}

In Figure 4a, the evolution of hydrogen during the immersion of samples in SBF is shown. The kinetics appears to be exponential at the very start of corrosion, before changing to linear or apparently constant (in the case of X03). The reaction boosts after the replenishments of SBF at 7 and 14 days can be clearly seen. After the replenishments, the kinetics seems to become more complex, especially in the Z5 sample. The rates of corrosion derived from the hydrogen evolution are shown 
in Figure $4 \mathrm{~b}$. The corrosion rates for Mg may differ depending on various parameters: the degree of its purity, heat treatment of the material, the type of electrolyte, the time of immersion, the crystal orientation, etc. $[6,7,17,26-31]$. As reported, $\mathrm{Mg}$ in the high-purity form has the lowest corrosion rate, below $1 \mathrm{mlcm}^{-2} \mathrm{day}^{-1}$. However, heat treatment causes its corrosion rate to increase to $1-5$ $\mathrm{mlcm}^{-2} \mathrm{day}^{-1}$ [30]. On the other hand, corrosion rates of as-cast pure $\mathrm{Mg}$ (melted from $99.98 \mathrm{wt} \% \mathrm{Mg}$ ), under a short time of immersion (i.e., $2 \mathrm{~h}$ ) may be up to $17 \mathrm{mlcm}^{-2} \mathrm{day}^{-1}$ [31], and in commercially pure $\mathrm{Mg}$, exposed in SBF for $24 \mathrm{~h}$, they are approximately 6-7 $\mathrm{mlcm}^{-2}$ day $^{-1}$ [26]. However, due to the fact that the degradation behavior of the $\mathrm{Mg}$ alloy is always related to its surrounding environment [31], and the chosen experimental set-up, the evolution of corrosion rates over time is rather complex (Figure 4 b). A significant non-zero rate after first 2-3 days is only observed in ZX50. In Figure 4a, both the exponential start as well as the linear continuation of hydrogen evolution can be very clearly observed for ZX50. Thus, we tried to fit these first 4 days using the sum of an exponential and linear function, $E+L . E=a\left(1-\mathrm{e}^{-b t}\right)$ is the so-called increasing form exponential decay, which increases rapidly at first, and then levels off to some asymptotic value. It is used to describe the early stages of the reaction. $L=c t+d$ is the linear component, supposed to correspond to the later stages of the reaction. A nearly-identical shape is found in the literature for $\mathrm{H}_{2}$ evolution tests on pure $\mathrm{Mg}$ using $\mathrm{SBF}$ with a TRIS/HCl buffer [26]. The results for ZX50 are shown in Figure 4c. The same fits were made for $\mathrm{X} 03$ and $\mathrm{Z} 5$, and the rates, $d(E+L) / d t$, were then calculated. The rates for the exponential part, $d E / d t$, are shown in Figure $4 \mathrm{~d}$. All of the $d E / d t$ rates become zero after 2.5 days. The linear parts, $d L / d t$, for X03, Z5 and ZX50 amount to $0.06,0.11$ and $0.82 \mathrm{mlcm}^{-2} \mathrm{day}^{-1}$, respectively. Thus, even if the linear part rates for X03 and Z5 are considerably smaller than for ZX50, they are not zero, as is suggested by Figure $4 \mathrm{~b}$. $E$ and $L$ could correspond to first-order and zero-order reactions taking place during the corrosion process. In the future, this could help in identifying the reactions involved.
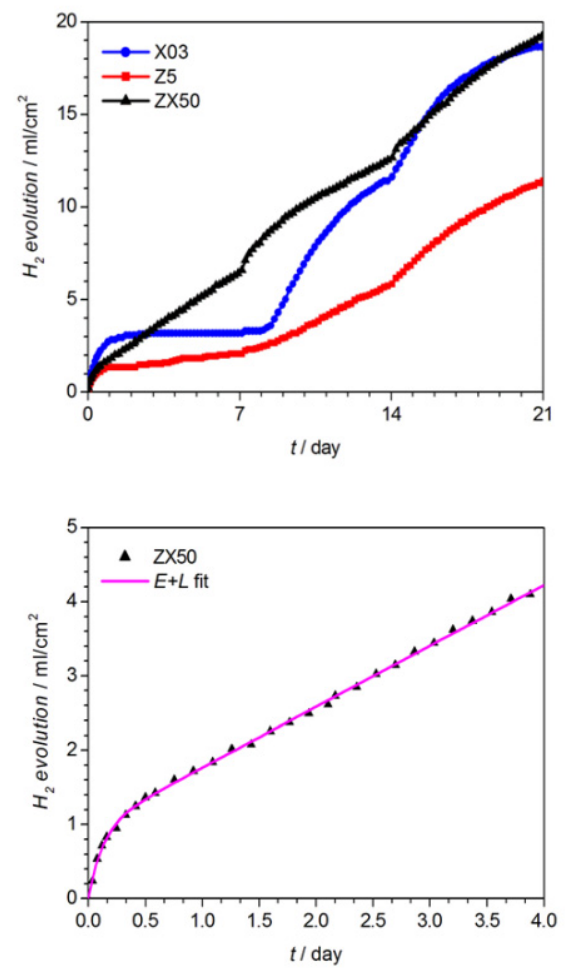

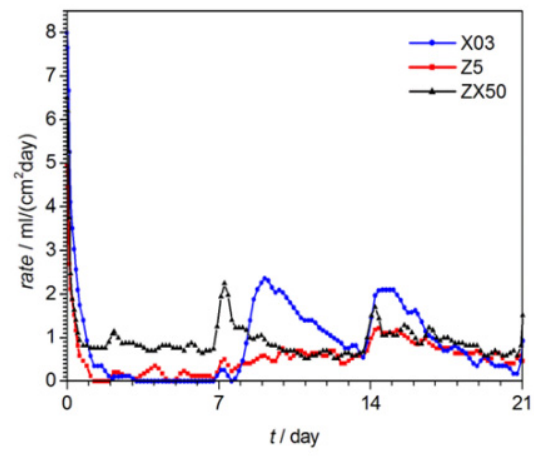

d

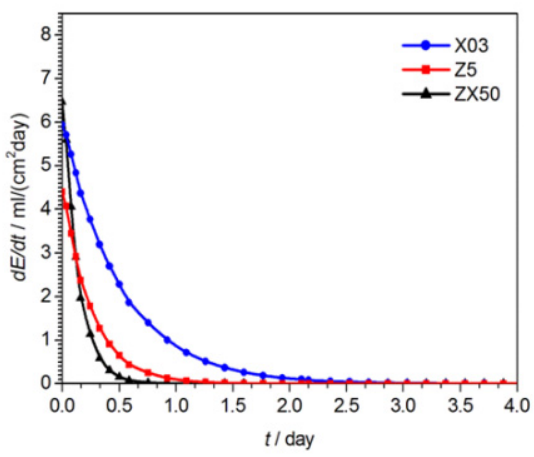

Figure 4. $\mathrm{H}_{2}$ evolution (a), the corrosion rates (b), $\mathrm{H}_{2}$ evolution fitted by $E+L$ (c) and the rates for the exponential contribution $(\mathbf{d})$. 


\subsection{Analysis of Samples after SBF Immersion}

\subsubsection{Imaging}

Stereo microscope images of the three representative samples aimed at XPS analysis, after immersion in SBF, are shown in Figure 5. Comparison of the samples after three weeks of immersion in SBF (Figure 5) reveals the features and characteristics of exposed surfaces; parts of the samples are already missing in the case of both Zn-containing alloys, while the X03 alloy shows a rather homogenous corrosion behavior.

a

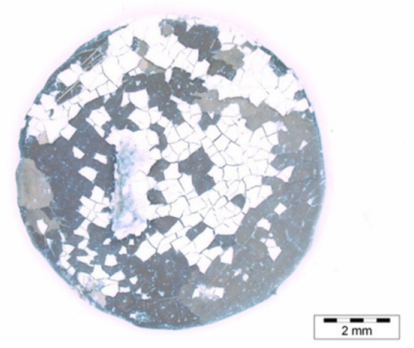

b

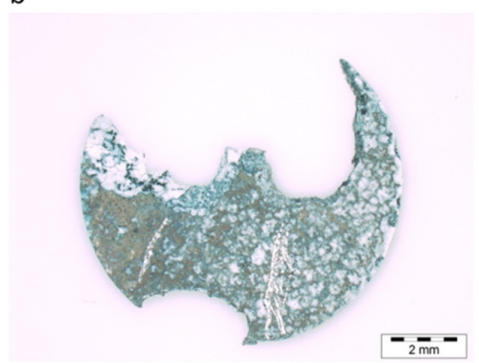

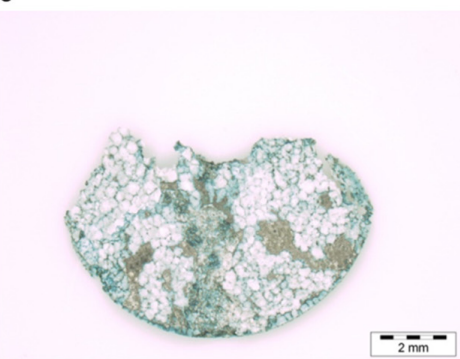

Figure 5. Stereo microscope images of samples X03 (a), Z5 (b) and ZX50 (c) after immersion in SBF.

SEM imaging of the surface was also attempted but, due to the strong charging of the surface, only two poor-quality SEM images were obtained, with brightness over-saturation on the upper surfaces (Figure 6). Nevertheless, at $60^{\circ}$ tilt of the sample, the lateral surface of a grain in the crack could be observed in one of the SEM images (Figure 6a), and a rough estimate of the degradation layer's thickness could be made, of the order of $100 \mu \mathrm{m}$. A somewhat larger area of the sample Z5 is shown in Figure 6b. Two points where localized Auger Electron Spectroscopy (AES) was attempted have been marked. However, no useful spectra were obtained due to strong surface charging. A tentative assessment of the surface layer thickness of the order of $100 \mu \mathrm{m}$ could be made from the deep crack in the bottom part of Figure $6 \mathrm{~b}$. The dimensions of the scales on the other samples are somewhat smaller, but are roughly of the same order of magnitude; thus, it can be tentatively concluded that thicknesses of the degradation layers are 10-100 $\mu \mathrm{m}$. The surface morphology is typical of $\mathrm{Mg}$ alloys exposed to buffered SBF, e.g., [26,27].

a

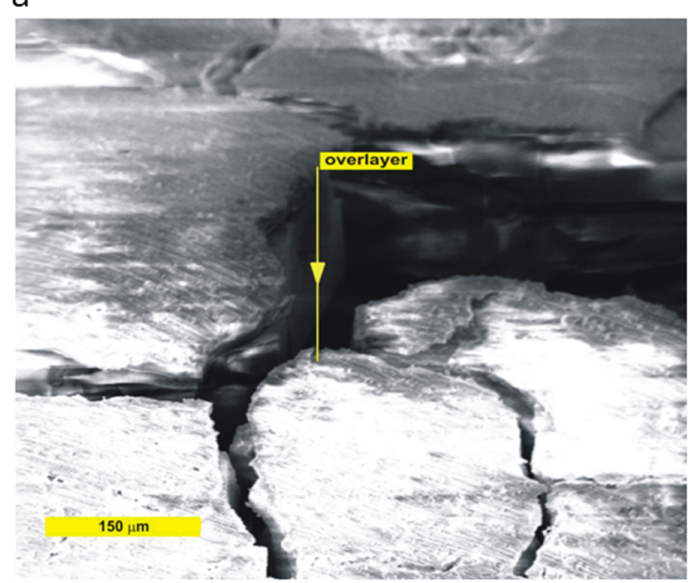

$\mathrm{b}$

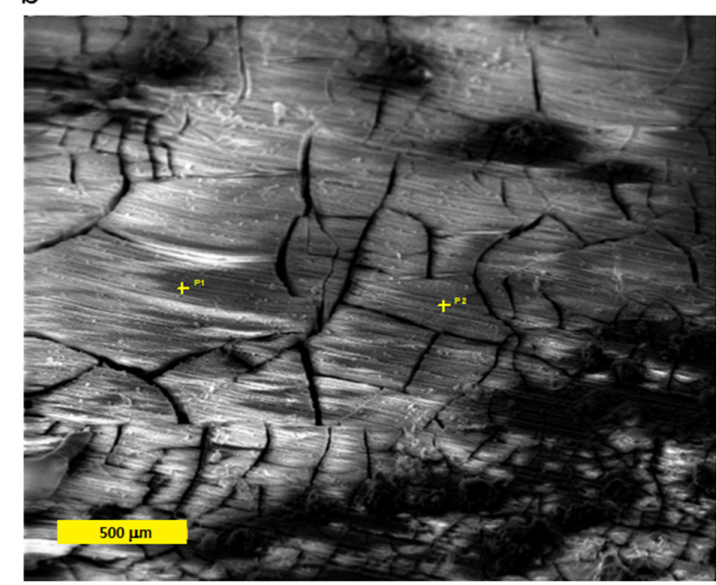

Figure 6. Typical low-magnification SEM images of cracks in the scaled degradation layer in sample X03 at higher (a) and Z5 at lower (b) magnification after immersion in the SBF. 


\subsubsection{XPS of Samples after SBF Immersion}

As concerns the investigations by XPS, several levels with increasing sputtering times of survey and XPS spectra were measured to ensure that the surface contaminants were removed by etching (Figure 7). The high-resolution spectra of some relevant elements were also measured (Figure 8).

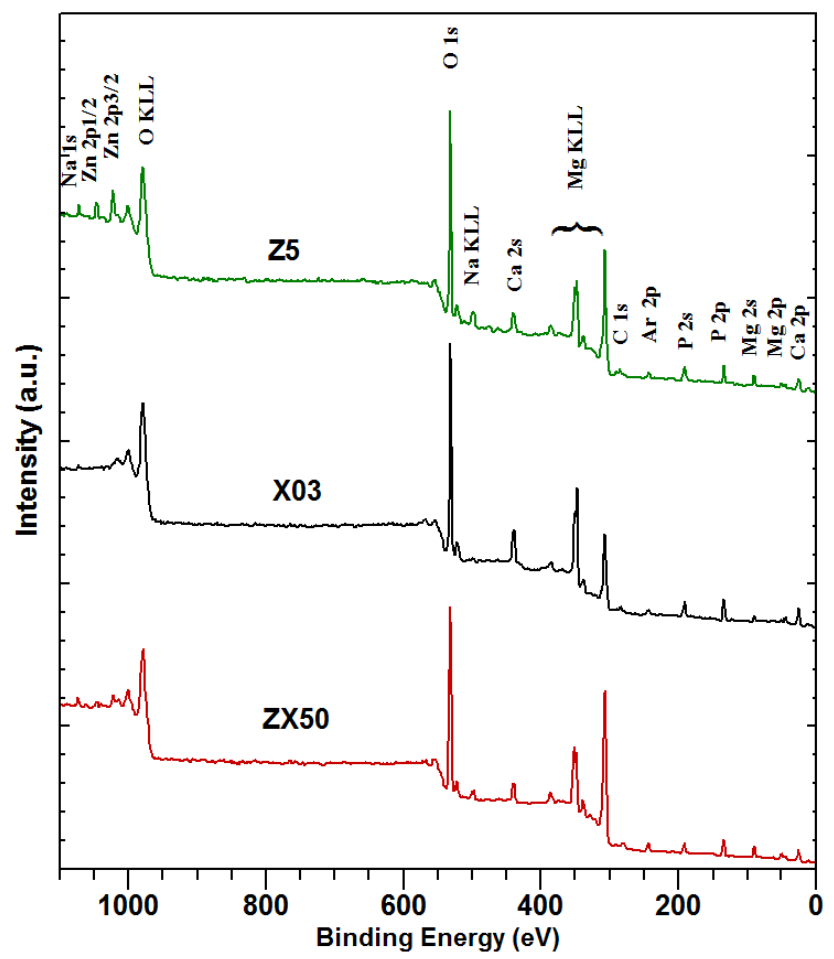

Figure 7. The survey XPS spectra of sputtered samples of ZX50, X03 and Z5 alloys after immersion in the SBF.

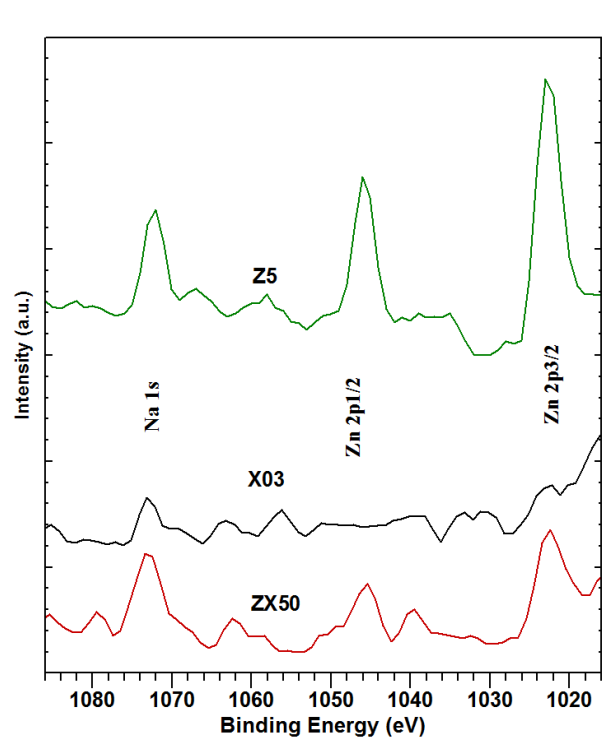

(a)

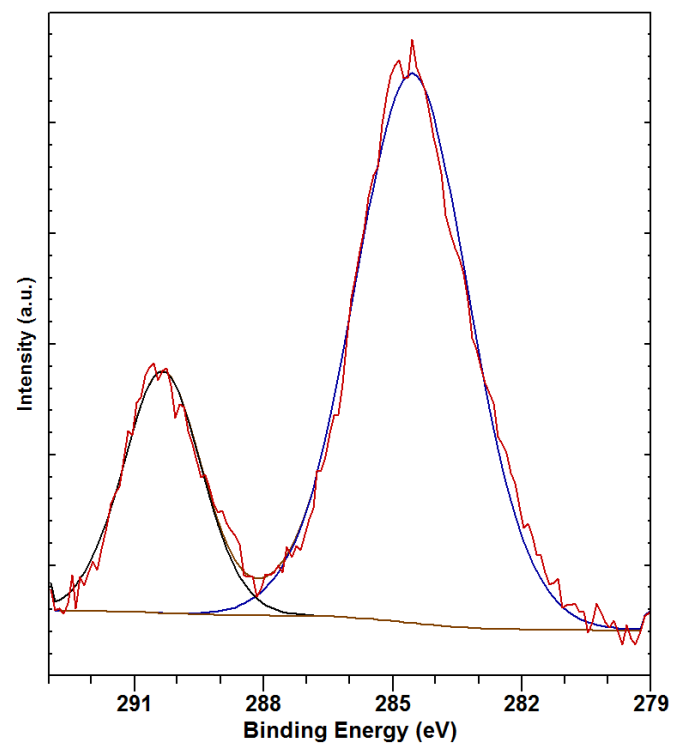

(b)

Figure 8. Narrow acquisition range XPS scans of 1016-1086 eV of the ZX50, X03 and Z5 alloys (from bottom to top) after immersion in SBF (a), and the HR XPS spectrum of C 1s fitted with components around $285 \mathrm{eV}$ and $290 \mathrm{eV}(\mathbf{b})$. 
Similar to the XPS spectra measured before the immersion in SBF, only the spectra from the finally-sputtered samples are shown in Figure 7, while the most of cleaning was already achieved after the first sputtering cycle.

In Figure 8a, a narrow acquisition range of XPS scans 1016-1086 eV for the ZX50, X03 and Z5 alloys (from bottom to top) is shown. Zn 2p3/2 at $1023 \mathrm{eV}, \mathrm{Zn} 2 \mathrm{p} 1 / 2$ at $1046 \mathrm{eV}$ and Na $1 \mathrm{~s}$ at $1073 \mathrm{eV}$ peaks are clearly visible in the spectra corresponding to ZX50 and Z5, but not in those representing the X03 alloy. Since the measured $\mathrm{Zn}$ concentrations in the Zn-containing samples are in the order of 1 at $\%$ (Table 4), and since corresponding peaks can be clearly seen in Figure 8a, this confirms the suspicion of surface $\mathrm{Zn}$ depletion in the samples before SBF immersion. The positions of the $\mathrm{Zn}$ and Na peaks suggest chemical states corresponding to zinc oxide and sodium (hydrogen) phosphate.

Table 4. Elemental concentrations in at $\%$ for elements detected at the top of the degradation layer in all measured alloys.

\begin{tabular}{cccc}
\hline Sample & X03 & Z5 & ZX50 \\
\hline $\mathrm{c}(\mathrm{Na})$ & 0.4 & 0.7 & 1.5 \\
$\mathrm{c}(\mathrm{Zn})$ & 0.0 & 1.0 & 0.5 \\
$\mathrm{c}(\mathrm{O})$ & 59.1 & 56.6 & 58.9 \\
$\mathrm{c}(\mathrm{Ca})$ & 14.5 & 8.9 & 8.9 \\
$\mathrm{c}(\mathrm{C})$ & 2.0 & 3.1 & 2.8 \\
$\mathrm{c}(\mathrm{P})$ & 15.2 & 11.0 & 13.2 \\
$\mathrm{c}(\mathrm{Mg})$ & 9.2 & 19.0 & 14.3 \\
\hline
\end{tabular}

In Figure 8b, the peaks corresponding to $\mathrm{C} 1 \mathrm{~s}$ are shown. The larger component around $285 \mathrm{eV}$ corresponds to the carbohydrate-based surface contamination, while the smaller component around $290 \mathrm{eV}$ corresponds to $\mathrm{C}$ in the carbonates. The first component decreases and the second one increases with sputtering time. Most of the change, however, is already accomplished after the first sputtering cycle, as was the case with the carbon-contamination removal in the samples before the SBF immersion. This finding is observed in all of the samples.

From the measured spectra of the sputtered samples, elemental concentrations were obtained for all samples (Table 4). Only the carbon pertaining to carbonates is taken into account in Table 4 . The share of this carbon is obtained by fitting the $\mathrm{C} 1$ s peaks with the components at $285 \mathrm{eV}$ and $290 \mathrm{eV}$, as shown in Figure 8b. However, the concentration values in Table 4 suggest that the carbonates do not form an important share of the degradation layer.

Importantly, a considerable amount of $\mathrm{Ca}$ is detected in the degradation layer on the $\mathrm{Z} 5$ alloy (Figure 7, Table 4) in spite of none being present in the original alloy (as verified by the composition measurement, Table 1, and XPS measurement, Figure 3). This is most likely due to $\mathrm{Ca}^{+}$and $\mathrm{HCO}_{3}{ }^{-}$ions from the SBF forming calcium carbonate that is deposited onto the sample surface. Also, comparing Table 1 with Table 3, it is clear that before the SBF immersion, the surface concentration of the initially-low Ca concentration is increased in the Ca-containing samples, although $\mathrm{Ca}$ is not detected in the $\mathrm{Z} 5$ sample. This increase could be due to the non-homogeneity of the topmost layer of the sample. There is a significant further increase of the Ca concentration during the SBF immersion (Tables 3 and 4). Since there is a significant Ca concentration on the Z5 sample after the SBF immersion, this Ca must have come from the solution. It is possible that some of the Ca on the X03 and ZX50 samples is also deposited from the SBF during immersion. It has also been found that during the phosphate deposition, the $\mathrm{Ca} / \mathrm{Mg}$ ratio increases for approximately $10 \mathrm{~h}$, which is followed by a slow decrease after $>100 \mathrm{~h}$ of immersion [28].

Table 4 shows that the concentrations of $\mathrm{Ca}, \mathrm{P}, \mathrm{Mg}$ and $\mathrm{O}$ are significantly larger than the concentrations of other detected elements in the degradation layer. A simplifying assumption was that most of the overlayer consists of apatite, magnesium phosphate and magnesium hydroxide, with $p, q$ and $r, p+q+r=1$ as their respective shares: $p\left[\mathrm{Ca}_{10}\left(\mathrm{PO}_{4}\right)_{6}(\mathrm{OH})_{2}\right]+q\left[\mathrm{Mg}_{\gamma} \mathrm{H}_{n}\left(\mathrm{PO}_{4}\right)_{2} \cdot x \mathrm{H}_{2} \mathrm{O}\right]+$ $r\left[\mathrm{Mg}(\mathrm{OH})_{2}\right] ; n$ is 1 or 2 , depending on the phosphate type. The second term is a generic form of (mono, 
di, tri) magnesium phosphate hydrate, while the third term is magnesium hydroxide, which is an expected product of the Mg alloy corrosion in SBF [29]. Magnesium phosphate is indicated by the ratio of the calcium concentration to the phosphorus concentration, being significantly lower than 1.66, which corresponds to the apatite (Table 4). The concentration data from Table 4 were used to calculate $p, q$ and $r$ for different values of $\gamma$, i.e., different types of magnesium phosphate (see Table 5). Determining $x$ was not attempted since it is difficult to estimate the share of oxygen as a contaminant. From Table 5, it is clear that apatite appears in all of the samples for all $\gamma$ values, usually with a low share of around 0.1. Magnesium phosphate hydrate appears with shares comparable to those of magnesium hydroxide, while in two cases, it is found to be even larger. The significantly larger share of magnesium hydroxide compared to magnesium phosphate hydrate in sample Z5 is consistent with a low phosphorus vs. magnesium concentration compared to that of the other samples. The apparently non-existent magnesium hydroxide in $\mathrm{X} 03$ for $\gamma=3$ suggests that tri-magnesium phosphate hydrate does not form in that sample.

Table 5. Parameters $p, q$ and $r$ of the proposed apatite-phosphate-hydroxide model for different types of phosphate.

\begin{tabular}{cccccccccc}
\hline Sample & \multicolumn{3}{c}{ X03 } & \multicolumn{3}{c}{ Z5 } & \multicolumn{3}{c}{ ZX50 } \\
\hline $\boldsymbol{\gamma}$ & $\mathbf{1}$ & $\mathbf{2}$ & $\mathbf{3}$ & $\mathbf{1}$ & $\mathbf{2}$ & $\mathbf{3}$ & $\mathbf{1}$ & $\mathbf{2}$ & $\mathbf{3}$ \\
\hline $\boldsymbol{p}$ & 0.15 & 0.20 & 0.30 & 0.05 & 0.05 & 0.20 & 0.05 & 0.10 & 0.10 \\
$\boldsymbol{q}$ & 0.30 & 0.35 & 0.70 & 0.15 & 0.15 & 0.05 & 0.25 & 0.35 & 0.55 \\
$\boldsymbol{r}$ & 0.55 & 0.45 & 0.00 & 0.80 & 0.80 & 0.75 & 0.70 & 0.55 & 0.35 \\
\hline
\end{tabular}

\section{Discussion}

From Table 5, it can be seen that in X03, the share of $\mathrm{Ca}$ and $\mathrm{Mg}$ phosphates is higher than in $\mathrm{Z} 5$ and

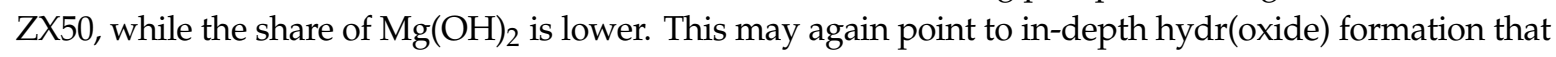
degrades the sample (Figure 5), as suggested in the discussion of the reaction dynamics (3.2.2.).

A comparison of the obtained results with the literature is limited in this work, since corrosion rates depend strongly on the measurement technique, corrosion medium and $\mathrm{pH}$ buffer capacity [32,33]. These were not varied and assessed in the present study. However, when comparing the three tested alloys, it can be seen from Figure $4 \mathrm{~b}$ that the corrosion rate is highest for the ternary ZX50 alloy-especially in the first days of immersion-while the binary Z5 alloy shows the lowest total hydrogen evolution (Figure 4a). These findings are consistent with our earlier report, where shorter times and an alternative technique for investigating the corrosion process were used [34].

When considering a material for biodegradable implant applications, at least two aspects of the degradation behavior are important.

First, the overall degradation rate should not be so high that the hydrogen gas evolving during the corrosion reaction leads to the formation of bubbles in the surrounding tissue [35]. This points to the $\mathrm{X} 03$ alloy as most appropriate of the three.

Second, the corrosion behavior should be homogeneous, and no pitting or localization of the corrosion reaction should occur, as this may lead to premature failure of the implant. An optical inspection of the samples after three weeks of exposure to SBF (Figure 5) shows that in case of both Zn-containing alloys, parts of the samples were already missing, while the X03 alloy showed rather homogenous corrosion behavior. Thus, this alloy may be the best one to be considered for implant applications-at least from the viewpoint of degradation behavior. However, the mechanical properties of this alloy are usually insufficient for appropriate structural performance, and therefore, other biocompatible alloying elements, e.g., Zn, should be added for solid-solution or precipitation strengthening $[7,20]$.

The mechanical properties, mainly the strength, are also crucial in view of the applicability of biodegradable implants $[5,7,16,17,20]$. It should be noted, therefore, that all of the alloys investigated in this study were in solid solution-treated condition. Different processing techniques can significantly 
affect not only mechanical properties, as reported by Horky et al. [36], but also the corrosion rate of Mg-alloys, as shown by Ojdanic et al. $[37,38]$. The low hydrogen evolution rate in the alloy Z5 and corrosion rate in alloy X03, along with the high corrosion rate in ZX50, indirectly suggest that the heat treatment of the last was not optimal. This may lead to residual primary precipitate particles remaining in the microstructure, which in turn leads to an accelerated corrosion rate. These will be further investigated and optimized in forthcoming studies.

Large missing parts in the Z5 and ZX50 samples (Figure 5b,c) may also suggest that $E$ and $L$, the exponential and linear reaction components, are responsible for the surface degradation layer growth and in-depth (hydr)oxide growth, respectively. The reaction in sample X03 virtually stops after 2 days (Figure $4 a, b$ ) when the exponential component $E$ approaches 0 (Figure $4 d$ ). It can be speculated that during this phase, more surface oxide forms than in samples Z5 and ZX50, where $E$ disappears faster (Figure 4d). This surface oxide on X03 serves as a barrier against in-depth corrosion.

\section{Summary and Conclusions}

Two binary biodegradable Mg-alloys and one ternary biodegradable Mg-alloy (Mg-0.3Ca, Mg-5Zn and Mg-5Zn-0.3Ca, all in wt $\%), X 03, \mathrm{Z} 5$ and ZX50, respectively, in solid-solution state were investigated before and after in vitro bio-corrosion immersion tests in SBF.

The surface chemical composition of all the samples before the immersion in SBF can be described as follows: several oxygen components were observed for all of the samples, with the $\mathrm{O} 1 \mathrm{~s}$ binding energy being consistent with different hydroxides, oxides, phosphates and carbonates. $\mathrm{Mg} 2 \mathrm{~s}$ and $\mathrm{Ca}$ $2 \mathrm{~s}$ binding energies are consistent with magnesium (hydr)oxides and carbonates. The carbonates were only present in small concentrations or not at all, since a corresponding carbonate component of the $C$ 1s peak could not be observed. Before immersion, $\mathrm{Zn}$ was not observed at all on the surface of any of the sample. This might be due to the low average concentration of Zn (at the XPS detection threshold), possibly enhanced by a non-homogeneous composition of the surface layer relative to the bulk. At the same time, significant $\mathrm{Ca}$ enrichment in both Ca-containing samples was observed.

The progress of reactions during the SBF immersion was followed by monitoring the evolution of $\mathrm{H}_{2}$. An exponential-linear model was proposed for the reaction kinetics during the first stage of immersion.

The XPS results suggest that the typical bio-corrosion products on the $\mathrm{Mg}-0.3 \mathrm{Ca}, \mathrm{Mg}-5 \mathrm{Zn}$ and Mg-5Zn-0.3Ca alloys consist of Mg, Ca, P and O. The surface concentrations are consistent with magnesium hydrogen phosphate and magnesium hydroxide, with up to $20 \%$ of apatite (calcium phosphate hydroxide).

Based on the reaction dynamics and the post immersion surface composition results, as well as optical images of the post immersion samples, it is suggested that the linear contribution to the reaction rate is related to the in-depth corrosion and sample degradation.

Considering the applicability of the analyzed alloys as materials for biodegradable implant applications, the overall degradation rate points to the $\mathrm{Mg}-\mathrm{Ca}$ alloy $(\mathrm{XO3})$ as the most appropriate of the three. As for the structural integrity of the sample after long immersion periods, the optical inspection of the samples again points at this alloy.

Nevertheless, the considerations of higher structural properties, when required, suggest also the alloy ZX50 as a potent candidate upon further optimization of the thermo-mechanical treatment.

Author Contributions: Conceptualization, D.O., B.Š., and M.J.Z.; methodology, J.H., D.S.P., D.M., D.O., and M.J.Z.; sample preparation \& investigation, A.O., J.H., D.S.P., and D.M.; writing-original draft preparation, D.S.P., D.M., and J.H.; writing—review and editing, J.H., D.S.P. and D.M.; supervision, D.O., B.Š., M.J.Z. All authors have read and agreed with the published version of the manuscript.

Funding: The authors acknowledge the financial support from the Slovenian Research Agency (project J2-7157, and research core funding of P2-0132 and P2-0162). This research was also financed by the Austrian Science Fund (FWF) within project I2815-N36.

Conflicts of Interest: The authors declare no conflicts of interest. 


\section{References}

1. Müller, L.; Müller, F.A. Preparation of SBF with different $\mathrm{HCO}_{3}{ }^{-}$content and its influence on the composition of biomimetic apatites. Acta Biomater. 2006, 2, 181-189. [CrossRef] [PubMed]

2. Witte, F. The history of biodegradable magnesium implants: A review. Acta Biomater. 2010, 6, 1680-1692. [CrossRef] [PubMed]

3. Mohamed, A.; El-Aziz, A.M.; Breitinger, H.J. Study of the degradation behavior and the biocompatibility of Mg-0.8Ca alloy for orthopedic implant applications. J. Magnes. Alloy 2019, 7, 249-257. [CrossRef]

4. Chen, Y.J.; Wang, Q.D.; Lin, J.B.; Liu, M.P.; Hjelen, J.; Roven, H.J. Grain refinement of magnesium alloys processed by severe plastic deformation. Trans. Nonferr. Met. Soc. China 2014, 24, 3747-3754. [CrossRef]

5. Qi, F.; Zhang, D.; Zhang, X.; Xu, X. Effect of Sn addition on the microstructure and mechanical properties of Mg-6Zn-1Mn (wt. \%) alloy. J. Alloy Compd. 2014, 585, 656-666. [CrossRef]

6. Liu, Y.; Liu, D.; Zhao, Y.; Chen, M. Corrosion degradation behavior of Mg-Ca alloy with high Ca content in SBF. Trans. Nonferr. Met. Soc. China 2015, 25, 3339-3347. [CrossRef]

7. Witte, F.; Hort, N.; Vogt, C.; Cohen, S.; Kainer, K.U.; Willumeit, R.; Feyerabend, F. Degradable Biomaterials Based on Magnesium Corrosion. Curr. Opin. Solid State Mater. Sci. 2008, 12, 63-72. [CrossRef]

8. Du, X.; Yang, Q.; Chen, Y.; Yang, Y.; Zhang, Z. Galvanic corrosion behavior of copper/titanium galvanic couple in artificial seawater. Trans. Nonferr. Met. Soc. China 2014, 24, 570-581. [CrossRef]

9. Bakhsheshi-Rad, H.R.; Hamzah, E.; Daroonparvar, M.; Yajid, M.A.M.; Kasiri-Asgarani, M.; Abdul-Kadir, M.R.; Medraj, M. In-vitro degradation behavior of $\mathrm{Mg}$ alloy coated by fluorine doped hydroxyapatite and calcium deficient hydroxyapatite. Trans. Nonferr. Met. Soc. China 2014, 24, 2516-2528. [CrossRef]

10. Zheng, Y.F.; Gu, X.N.; Witte, F. Biodegradable metals. Mater. Sci. Eng. R Rep. 2014, 77, 1-34. [CrossRef]

11. Hornberger, H.; Virtanen, S.; Boccaccini, A.R. Biomedical coatings on magnesium alloys-A review. Acta Biomater. 2012, 8, 2442-2455. [CrossRef] [PubMed]

12. Chu, C.; Han, X.; Bai, J.; Xue, F.; Chu, P. Surface modification of biomedical magnesium alloy wires by micro-arc oxidation. Trans. Nonferr. Met. Soc. China 2014, 24, 1058-1064. [CrossRef]

13. Chen, B.; Wang, R.; Peng, C.; Feng, Y.; Wang, N. Influence of Al-Mn master alloys on microstructures and electrochemical properties of Mg-Al-Pb-Mn alloys. Trans. Nonferr. Met. Soc. China 2014, 24, 423-430. [CrossRef]

14. Shadanbaz, S.; Dias, G.J. Calcium phosphate coatings on magnesium alloys for biomedical applications: A review. Acta Biomater. 2012, 8, 20-30. [CrossRef]

15. Ilich, J.Z.; Kerstetter, J.E. Nutrition in Bone Health Revisited: A Story beyond Calcium. J. Am. Coll. Nutr. 2000, 19, 715-737. [CrossRef]

16. Li, Z.; Gu, X.; Lou, S.; Zheng, Y. The development of binary Mg-Ca alloys for use as biodegradable materials within bone. Biomaterials 2008, 29, 1329-1344. [CrossRef]

17. Gu, X.; Zheng, Y.; Cheng, Y.; Zhong, S.; Xi, T. In vitro corrosion and biocompatibility of binary magnesium alloys. Biomaterials 2009, 30, 484-498. [CrossRef]

18. Prashanth, L.; Kattapagari, K.K.; Chitturi, R.T.; Baddam, V.R.; Prasad, L.K. A review on role of essential trace elements in health and disease. J. NTR Univ. Health Sci. 2015, 4, 75-85.

19. Stefanidou, M.; Maravelias, C.; Dona, A.; Spiliopoulou, C. Zinc: A multipurpose trace element. Arch. Toxicol. 2006, 80, 1. [CrossRef]

20. Haenzi, A.C.; Sologubenko, A.S.; Gunde, P.; Schinhammer, M.; Uggowitzer, P.J. Design considerations for achieving simultaneously high-strength and highly ductile magnesium alloys. Philos. Mag. Lett. 2012, 92, 417-427. [CrossRef]

21. Haenzi, A.C.; Dalla Torre, F.H.; Sologubenko, A.S.; Gunde, P.; Schmid-Fetzer, R.; Kuehlein, M.; Loeffler, J.F.; Uggowitzer, P.J. Design strategy for microalloyed ultra-ductile magnesium alloys. Philos. Mag. Lett. 2009, 89, 377-390. [CrossRef]

22. Koike, J. Dislocation Plasticity and Complementary Deformation Mechanisms in Polycrystalline Mg Alloys. In Materials Science Forum; Trans Tech Publications Ltd.: Stafa-Zurich, Switzerland, 2004; Volume 449-452, pp. 665-668.

23. Fairley, N. CasaXPS VAMAS Processing Software. Available online: http://www.casaxps.com (accessed on 14 January 2019). 
24. Naumkin, A.V.; Kraut-Vass, A.; Gaarenstroom, S.W.; Powell, C.J. NIST: X-ray Photoelectron Spectroscopy Database. Available online: http://srdata.nist.gov/xps/ (accessed on 14 January 2019).

25. Chastain, J. (Ed.) Handbook of X-Ray Photoelectron Spectroscopy; Physical Electronics Inc.: Eden Prairie, MN, USA, 1995.

26. Mei, D.; Lamaka, S.V.; Gonzalez, J.; Feyerabend, F.; Willumeit-Römerb, R.; Zheludkevich, M.L. The role of individual components of simulated body fluid on the corrosion behavior of commercially pure Mg. Corros. Sci. 2019, 147, 81-93. [CrossRef]

27. Kieke, M.; Feyerabend, F.; Lemaitre, J.; Behrens, P.; Willumeit-Römer, R. Degradation rates and products of pure magnesium exposed to different aqueous media under physiological conditions. BioNanoMatererials 2016, 17, 131-143. [CrossRef]

28. Gray-Munro, J.E.; Strong, M. The mechanism of deposition of calcium phosphate coatings from solution onto magnesium alloy AZ31. J. Biomed. Mater. Res. Part A 2009, 90, 339-350. [CrossRef] [PubMed]

29. Gonzalez, J.; Hou, R.Q.; Nidadavolu, E.P.S.; Willumeit-Römer, R.; Feyerabend, F. Magnesium degradation under physiological conditions-Best practice. Bioact. Mater. 2018, 3, 174-185. [CrossRef]

30. Atrens, A.; Song, G.L.; Cao, F.; Shi, Z.; Bowen, P. Advances in Mg corrosion and research suggestions. J. Magnes. Alloy 2013, 1, 177-200. [CrossRef]

31. Ding, Y.F.; Li, Y.; Lin, J.; Wen, C. Effects of zirconium and strontium on the biocorrosion of Mg-Zr-Sr alloys for biodegradable implant applications. J. Mater. Chem. B 2015, 3, 3714-3729. [CrossRef]

32. Kirkland, N.T.; Birbilis, N.; Staiger, M.P. Assessing the corrosion of biodegradable magnesium implants: A critical review of current methodologies and their limitations. Acta Biomater. 2012, 8, 925-936. [CrossRef]

33. Mueller, W.D.; Nascimento, M.L.; Lorenzo de Mele, M.F. Critical discussion of the results from different corrosion studies of $\mathrm{Mg}$ and $\mathrm{Mg}$ alloys for biomaterial applications. Acta Biomater. 2010, 6, 1749-1755. [CrossRef]

34. Orlov, D.; Reinwalt, B.; Tayeb-Bey, I.; Wadsö, L.; Horky, J.; Ojdanic, A.; Schafler, E.; Zehetbauer, M. Advanced Immersion Testing of Model Mg-Alloys for Biomedical Applications. In Magnesium Technology 2020; The Minerals, Metals \& Materials Series; Jordon, J.B., Miller, V., Eds.; Springer International Publishing: Cham, Switzerland, 2020; pp. 235-242.

35. Kuhlmann, J.; Bartsch, I.; Willbold, E.; Schuchardt, S.; Holz, O.; Hort, N.; Höche, D.; Heineman, W.R.; Witte, F. Fast Escape of Hydrogen From Gas Cavities Around Corroding Magnesium Implants. Acta Biomater. 2013, 9 , 8714-8721. [CrossRef]

36. Horky, J.; Ghaffar, A.; Werbach, K.; Mingler, B.; Pogatscher, S.; Schäublin, R.; Setman, D.; Uggowitzer, P.J.; Löffler, J.F.; Zehetbauer, M.J. Exceptional Strengthening of Biodegradable Mg-Zn-Ca Alloys through High Pressure Torsion and Subsequent Heat Treatment. Materials 2019, 12, 2460. [CrossRef] [PubMed]

37. Ojdanic, A. Optimization of Mechanical Properties of Biodegradable Low-Corrosion Mg-Alloys by Means of Severe Plastic Deformation and Thermal Treatment. Ph.D. Thesis, University of Vienna, Vienna, Austria, 2019.

38. Ojdanic, A.; Horky, J.; Mingler, B.; Fanetti, M.; Gardonio, S.; Valant, M.; Sulkowski, B.; Schafler, E.; Orlov, D.; Zehetbauer, M.J. Effects of Severe Plastic Deformation and/or Thermal Treatment on Mechanical Properties of Biodegradable Mg-Alloys. Manuscript in preparation.

(C) 2020 by the authors. Licensee MDPI, Basel, Switzerland. This article is an open access article distributed under the terms and conditions of the Creative Commons Attribution (CC BY) license (http://creativecommons.org/licenses/by/4.0/). 